\title{
Laparoscopic conservative treatment of colo-vesical fistula: a new surgical approach
}

Cochetti Giovanni, Cottini Emanuele, Barillaro Francesco, Lepri Emanuele, Boni Andrea, Pohja Solajd, Mearini Ettore

Department of surgical specialties and Public Health, Urological Andrological Surgery and Minimally Invasive Techniques, University of Perugia, Perugia-Terni, Italy

\section{ABSTRACT}

Introduction: The standard treatment of colo-vesical fistula is the exeresis of fistula, suture of bladder wall, colic resection with or without temporary colostomy. Usually the approach is open because conversion rates and morbidity are lower than laparoscopy. The aim of video is to show the steps of a new mini-invasive approach of colo-vesical fistula without colic resection.

Materials and Methods: A 69 years old male underwent laparoscopic conservative treatment of colo-vesical fistula due to endoscopic polipectomy in sigmoid diverticulum. $12 \mathrm{~mm}$ trocar for the camera was placed at the umbilicus, two $10 \mathrm{~mm}$ trocars were placed along bisiliac line and $5 \mathrm{~mm}$ port was placed along left emiclavear line; Trendelenburg position was $20^{\circ}$. The fistulous loop was carefully isolated, clipped with Hem-o-lock ${ }^{\circledR}$ clips and removed. Since diverticular disease appeared slight and no inflammation signs were evident, colon resection was not performed. We sutured and sinked the sigmoid wall; after curettage of the fistula site, the bladder wall was sutured. Fat tissue was placed between sigmoid and bladder wall to reduce the risk of fistula recurrence.

Results: Operative time, estimated blood loss, catheterization time, time to flatus and hospital stay were respectively 210 minutes, $300 \mathrm{~mL}, 10$ days, $48 \mathrm{~h}$ and 8 days. The histological examination showed colonic inflammatory and necrotic tissue. No complications or fistula recurrence occurred at 54 months follow-up.

Conclusions: The laparoscopic conservative treatment of colo-vesical fistula is a safe and feasible technique, in particular when the diverticular disease is limited and the fistula is not due to diverticulitis.

\section{ARTICLE INFO}

Available at: www.brazjurol.com.br/videos/september_october_2013/Giovanni_752_753video.htm

Int Braz J Urol. 2013; 39 (Video \#11): 752-3

Submitted for publication: March 20, 2013

Accepted after revision: June 15, 2013
Correspondence address:

Cochetti Giovanni, MD

Department of surgical specialties and Public Health Urological Andrological Surgery and Minimally Invasive Techniques, University of Perugia, Perugia-Terni, Italy E-mail: giovannicochetti@libero.it 
EDITORIAL COMMENT

Giovanni and colleagues present a a simple and innovative technique for management of select colo-vesical fistulae. This is an important addition to the armamentarium available for the surgeon dealing with these cases.

\author{
A. Karim Kader, $M D$ \\ Associate Professor \\ Department of Urology \\ University of San Diego \\ San Diego, CA, USA \\ E-mail:jmthompson@ucsd.edu
}

